\title{
A Rare Genetic Diseases; Incontinentia Pigmenti: A Case Report.
}

\author{
A.Rasso*, k.Boukhari, H.Baybay, S. Elloudi, Z. Douhi, FZ. Mernissi \\ Department of dermatology CHU Hassan II Fez Morocco.
}

*Corresponding author: Rasso Asmae, Department of dermatology CHU Hassan II Fez Morocco.

Received date: February 26, 2020; Accepted date: March 03, 2020; published date: March 06,2020

Citation: A A.Rasso, k.Boukhari, H.Baybay, S. Elloudi, Z. Douhi, FZ. Mernissi A Rare Genetic Diseases; Incontinentia Pigmenti: A Case Report. J Clinical Research and Reports, 3(3); DOI:10.31579/2690-1919/060

Copyright: (C) 2020 A.Rasso. This is an open access article distributed under the Creative Commons Attribution License, which permits unrestricted use, distribution, and reproduction in any medium, provided the original work is properly cited.

\section{Abbreviations used:}

MRI: magnetic resonance imaging.

IP: Incontinentia pigmenti.

Key words: Incontinentia pigmenti; Girl; Genetic Diseases

\section{Clinical image}

A 3 years-old girl, born of a 25-year-old mother, and of 30-year-old father, with a 1st degree consanguineous marriage. She was born full term after an uneventful pregnancy. History of similar disease was not present in her family. The parents consulted pour management of skin lesion. with no associated functional signs including no mental retardation, no epilepsy. they report that her skin had been fiery red at the birth time and vesicles had developed shortly afterwards. Then the lesions had cleared gradually and left linear hypo-pigmentation. On clinical examination, showed a facial asymmetry, especially mandibular. Hypopigmented atrophic streaks were seen in her face abdomen, back and limbs, with a baschko-linear path. And she had a syndactyly from the toes of the feet. And. The disease was diagnosed as Incontinentia pigmenti (IP). The ophthalmic exam was normal. Her genetic counseling was otherwise normal. A dental radio-panoramic, and MRI of the cerebral, and lumbosacral spine have been requested.

Incontinentia pigmenti (IP) is inherited in an X-linked dominant manner. Therefore, more than $95 \%$ of patients are female infants. It's a rare syndrome with skin lesions, ocular abnormalities in the retina and elsewhere, central nervous system abnormalities, and teeth defects [1]. Dermatologic findings are often the first observed signs and classically evolve through four stages, including the stage 1 (vesicular stage), Stage 2 (verrucous stage), Stage 3 (hyperpigmented stage), and Stage 4 (atrophic/hypopigmented stage). Extracutaneous manifestations occur in various ways in about $70-80 \%$ of IP patients. Dental abnormalities are the most common types and affect more than $80 \%$ of patients with delayed dentition [2]. neurologic deficiency identified as seizures, mental retardation, developmental delays, spastic paralysis, ataxia and motor dysfunction [3]. Ocular abnormalities are also observed including nystagmus, strabismus, optic atrophy, retinal dysfunction, uveitis, cataracts, and blindness. Additionally, there are occasional reports on skeletal and structural anomalies such as skull deformities, somatic asymmetry, spina bifida, dwarfism, syndactyly, extra ribs, primary pulmonary hypertension, and cardiopulmonary failure. Several cases of IP have been associated with cancer in childhood and Keratotic tumors in late adolescence may involute spontaneously [4].

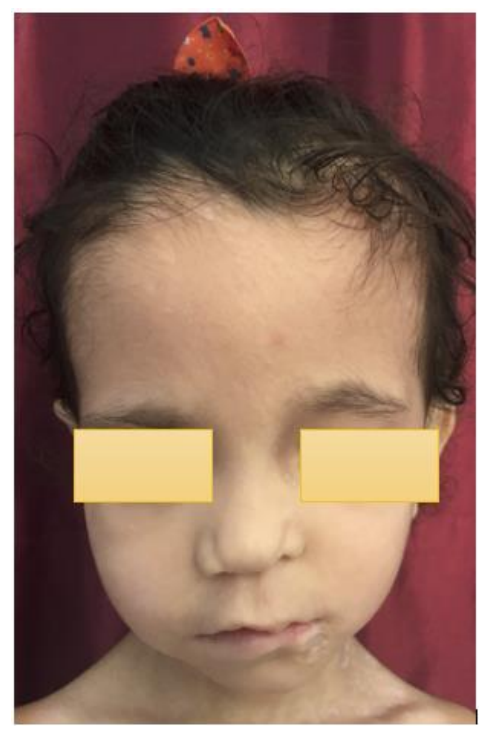

Figure 1: Hypopigmented atrophic streaks were seen in her face, and facial asymmetry especially mandibular. 

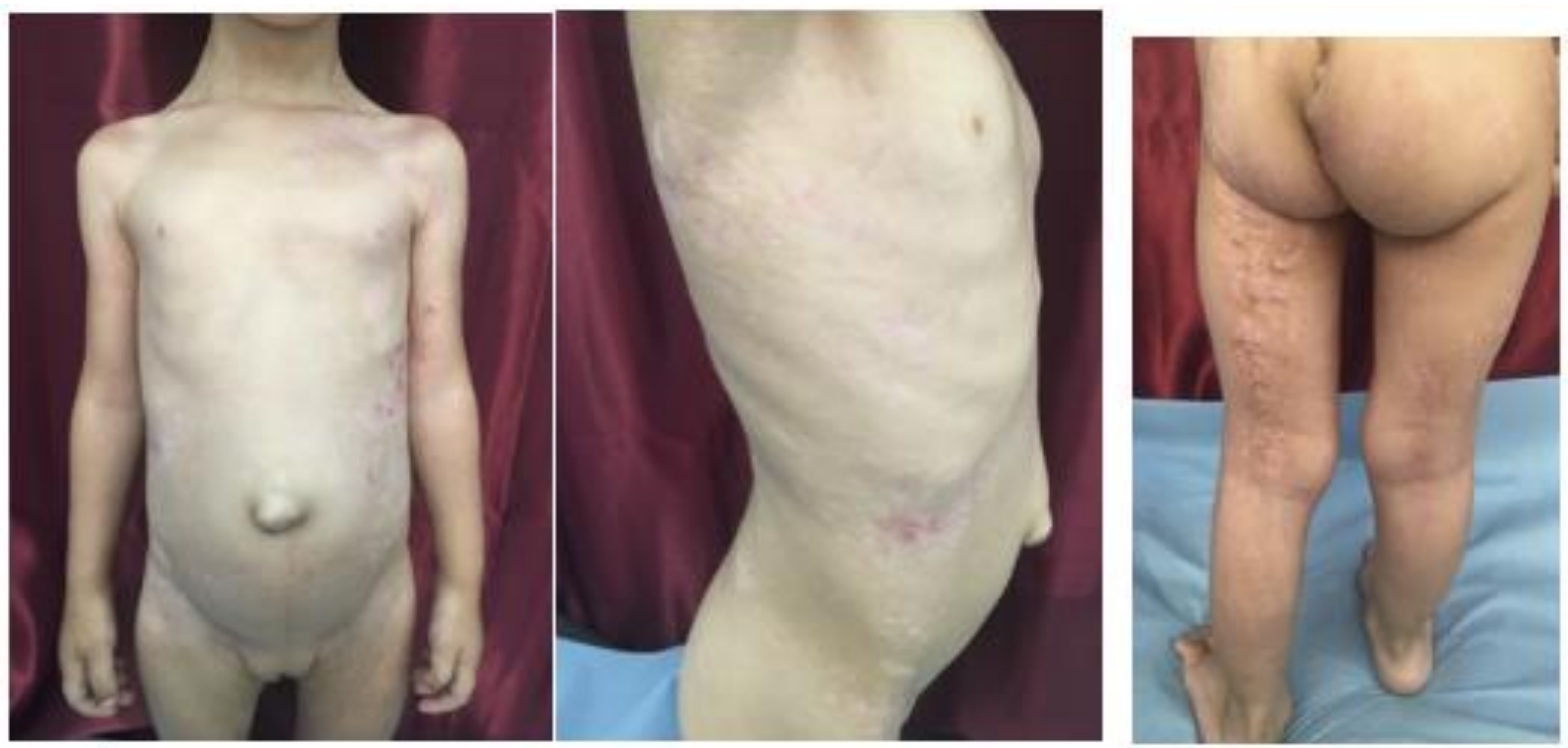

Figure 2: Hypopigmented atrophic streaks baschko-linear were seen in her abdomen, back and limbs.

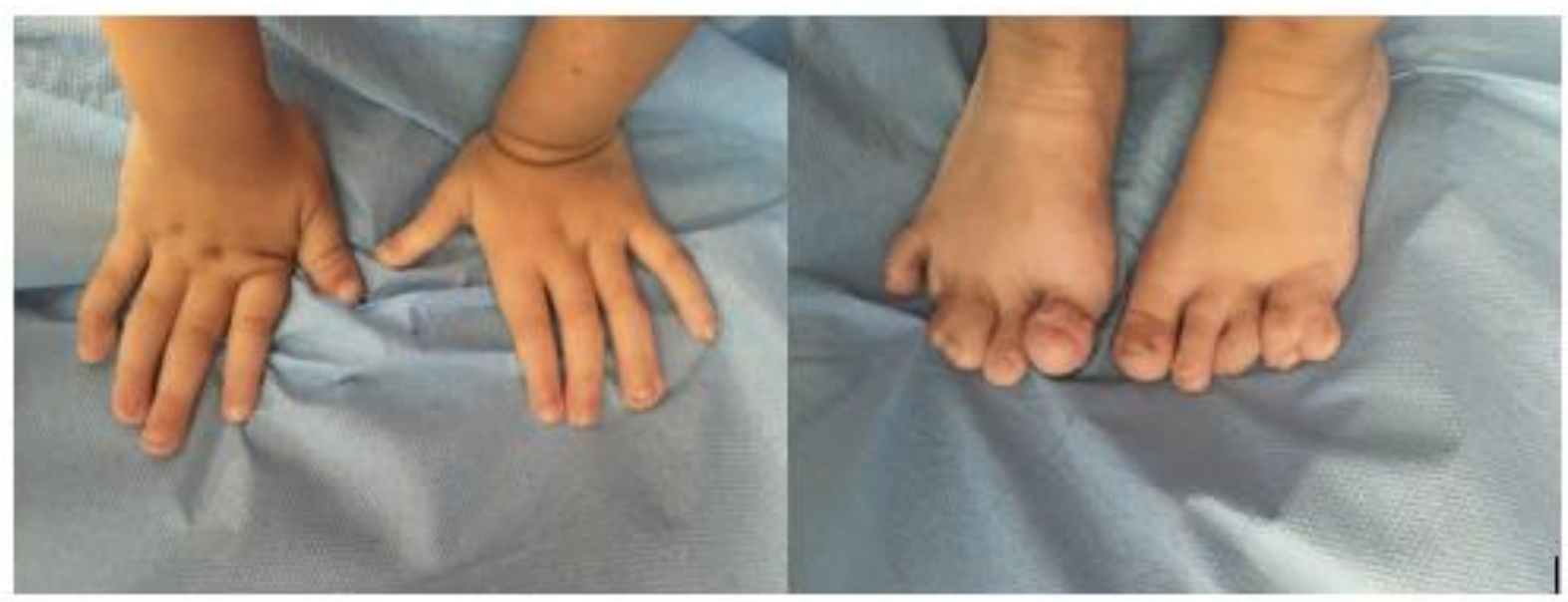

Figure 3: A syndactyly from the toes of the feet.

\section{Consent}

The examination of the patient was conducted according to the Declaration of Helsinki principles.

Conflict of Interest: I declare no conflict of interest

\section{References}

1. Swinney CC, Han DP, Karth PA. Incontinentia Pigmenti: A Comprehensive Review and Update. Ophthalmic Surg Lasers Imaging Retina. 2015; 46: 650-657.
2. Wu HP, Wang YL, Chang HH, Huang GF, Guo MK. Dental anomalies in two patients with incontinentia pigmenti. J Formos Med Assoc. 2005; 104: 427-430.

3. Clemons E, Clemons D, Lee JA, Berne S. Incontinentia pigmenti in three generations: A case report. J Am Acad Dermatol. 2008; 58: AB80.

4. Minić S, Trpinac D, Obradović M. In-continentia pigmenti diagnostic criteria update. Clin Genet. 2014; 85: 536-542. 